\title{
Deposition of $\mathrm{CoFe}_{2} \mathrm{O}_{4}$ Composite Thick Films and Their Magnetic, Electrical Properties Characterizations
}

\author{
W. Chen and W. Zhu \\ Microelectronics Center, School of Electrical and Electronic Engineering, \\ Technological University Nanyang \\ Singapore
}

\section{Introduction}

In recent years, spinel ferrites have been shown to exhibit interesting electrical conductivity and dielectric properties in their nanocrystalline form compared with that of the micrometer size grains (Ponpandian \& Narayanasamy, 2002; Sepelak et al., 2000; Dias \& Moreira, 1999). Typical examples of Ni-Zn ferrites and Co-ferrites have been extensively investigated: the former suggests that dielectric constant of nanostructured Ni-Zn ferrite is smaller than that of bulk ceramics (Sivakumar et al., 2008), but the situation is reversed for the Co-ferrites (Sivakumar et al., 2007). Fortunately the dielectric loss of nanostructured ferrites is hence reduced for both of them compared to their bulks. Furthermore, a non-Debye type of dielectric relaxation is observed in these ferrites, which is extensively expressed by electrical modulus (Sivakumar et al., 2008; Sivakumar et al., 2007; Perron et al., 2007). However, the detailed reports on cobalt ferrite, which is one of the potential candidates for magnetic and magneto-optical recording media (Kitamoto et al., 1999; Fontijin et al., 1999), have not drawn enough interests so far. Much attention has been paid on the synthesis of nanostructured cobalt ferrite particles as well as bulk ceramics or thin films (Toksha et al., 2008; Komarneni et al., 1998; Sathaye et al., 2003; Paike et al., 2007; Bhame \& Joy, 2008; Gul et al., 2008) and characterizations of their magnetic properties. As for their dielectric properties, which can provide important information on the behavior of localized electric charge carriers, giving rise to a better understanding of the mechanism of dielectric polarization, have attracted little attention except few reports on nanostructured $\mathrm{CoFe}_{2} \mathrm{O}_{4}$ powder (Sivakumar et al., 2007; George et al., 2007). Recently, more attention has been paid to the electric properties of the double-phase multiferroic composites, such as CFO-PZT, and CFO-BTO (Chen et al., 2010; Zhong et al., 2009), or its doping systems (Gul et al., 2007). While pure $\mathrm{CoFe}_{2} \mathrm{O}_{4}$, especially its thick film structure, which is a critical scale range for micro-electro-mechanical systems (MEMS) design, has not been found in the literatures.

In order to explore the processing of cobalt ferrite thick film and its electrical properties for potential MEMS development, the present work has adopted a similar fabrication to typical PZT ferroelectric thick films (Chen et al., 2009). $10 \mu \mathrm{m}$ of cobalt ferrite composite thick films is successfully prepared via a hybridized sol-gel processing. The influence of annealing temperature on the phase structures, microstructures, Raman shift, magnetic and electrical 
properties are well characterized. Furthermore, Ac conductivity spectra analysis is employed to investigate the ion motion nature of $\mathrm{CoFe}_{2} \mathrm{O}_{4}$ composite thick films. The detailed electrical investigations were conducted in the frequency range of $100 \mathrm{~Hz}-1 \mathrm{MHz}$ and temperature range between 25 and $200{ }^{\circ} \mathrm{C}$. Real and imaginary parts of impedance $\left(Z^{\prime}\right.$ and $Z^{\prime \prime}$ ) in the above frequency and temperature domain suggested the coexistence of two relaxation regimes: one was induced by electrode polarization; while the other was attributed to the co-effect of grains and grain boundaries, which was totally different from its counterpart of bulks and also not reported in other ferrites. Electrical modulus $\left(\mathrm{M}^{\prime}\right.$ and $\mathrm{M}^{\prime \prime}$ ) further showed the crossover from grains effect to grain boundaries effect with increasing measured temperature under the suppression of electrode polarization. A nonDebye relaxation behavior and two segments of frequency independent conductivity were observed in dielectric spectra, which was also consistent with the results of ac conductivity spectra. In the conductivity spectra, double power law and single power law were separately applied to the co-effect from grains and grain boundaries and electrode polarization effect. Moreover, the dc conductivity from both effects well obeyed the Arrhenius law and their activation energies were matching to the ones calculated from imaginary impedance peaks, the detailed physical mechanisms on them were finally discussed.

\section{Deposition of $\mathrm{CoFe}_{2} \mathrm{O}_{4}$ composite thick films}

\subsection{Experimental procedural}

$\mathrm{CoFe}_{2} \mathrm{O}_{4}$ (abbreviated as $\mathrm{CFO}$ ) sol-gel solution was prepared by mixing cobalt acetate, ferric nitrate, and polyvinylpyrrolidone together at $60{ }^{\circ} \mathrm{C}$ according to the molar ratio of 1: 2: 2 till a clear solution was obtained. Then $40 \mathrm{ml}$ of 2-methoxyethanol was added to get $0.125 \mathrm{M}$ of $\mathrm{CFO}$ sol-gel solution. The $\mathrm{pH}$ value of resultant dark-red CFO sol-gel solution was 4.2. In addition, modified CFO particles were prepared by a high energy ball milling method as reported previously (Chen et al., 2009), which showed an average particle size of $233 \mathrm{~nm}$. Next, the modified CFO particles were dispersed in the CFO solution with a mass ratio of 2:3, which is similar to the fabrication of hybridized PZT slurry (Chen et al., 2010), to get the uniform CFO slurry via an agate ball milling for 15 hours. The collected CFO slurry showed a black color and was immediately spin coated onto the $\mathrm{Pt} / \mathrm{Ti} / \mathrm{SiO}_{2} / \mathrm{Si}$ substrate alternatively with CFO sol-gel solution to obtain the dense CFO film. After each coating layer, the film was baked at $140{ }^{\circ} \mathrm{C}$ for 3 minutes to dry the solvent and then held at $300{ }^{\circ} \mathrm{C}$ for another 3 minutes to burn up the organic components. The resulting thick films were annealed in air at various temperatures from $550{ }^{\circ} \mathrm{C}$ to $700{ }^{\circ} \mathrm{C}$ for 1 hour each, and their thicknesses were measured via a surface profiler to be around $10 \mu \mathrm{m}$.

TGA and DTA were performed using a Thermal Analyzer (TA-60WS) with a heating rate of $2{ }^{\circ} \mathrm{C} / \mathrm{min}$. Phase structures were evaluated using an X-ray diffractometer (2400, Rigaku, $\mathrm{C} u \mathrm{~K}_{\alpha}$ radiation). Raman spectroscopic measurements were carried out with a WITEC CRM200 confocal Raman system. The excitation source is $532 \mathrm{~nm}$ laser $(2.33 \mathrm{eV})$. Surface and cross-sectional morphologies of the thick films were obtained using a Scanning Electron Microscope (JSM-5600LV). Magnetic properties were detected by a Lakeshore Vibration Sample Magnetometer (7404). After deposition of gold top electrodes with the size of 0.8 $\mathrm{mm} \times 0.8 \mathrm{~mm}$ on the surface of thick films using E-beam, impedance spectroscopy was measured by using a Solartron SI1260 impedance/gain-phase analyzer from $0.1 \mathrm{~Hz}$ to 1 $\mathrm{MHz}$ at room temperature. In addition, the detailed electrical properties of the thick films 
were measured by an Agilent 4294A precision impedance analyzer over $100 \mathrm{~Hz}-1 \mathrm{MHz}$ and $25-200{ }^{\circ} \mathrm{C}$ at the ac oscillation level of $100 \mathrm{mV}$. Each measured temperature was kept constant with an accuracy of $\pm 1^{\circ} \mathrm{C}$.

\subsection{Characterizations}

TGA/DTA analysis of the dried CFO slurry, dried at $110{ }^{\circ} \mathrm{C}$ for 24 hours, is shown in Fig. 1.

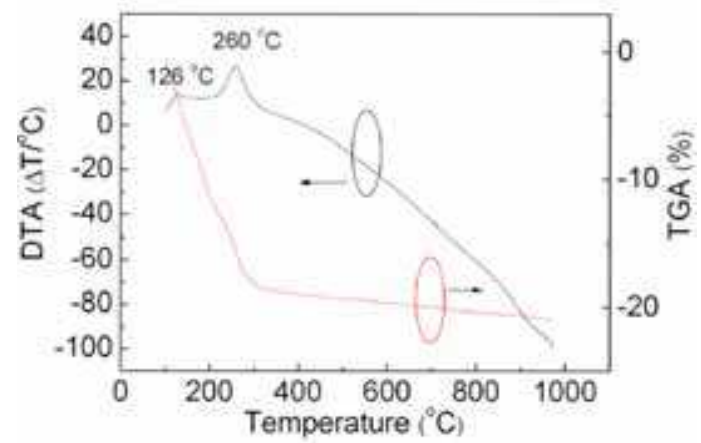

Fig. 1. DTA/TGA curves of the dried CFO slurry.

TGA yields a weight loss of $21 \mathrm{wt} \%$ before $300{ }^{\circ} \mathrm{C}$, and then nearly keeps stable until $800{ }^{\circ} \mathrm{C}$. In the DTA curve, two exothermic peaks are observed: one at $126^{\circ} \mathrm{C}$ which is due to the organic solvent evaporation; the other at $300^{\circ} \mathrm{C}$ symbols the decomposition and combustion of the bound organic species in the CFO slurry. Since that the CFO powder has been presintered at a high temperature of $1200 \circ \mathrm{C}$ before high energy ball milling, it has almost no effect on TGA/DTA analysis. The observations of weight loss and exothermic peak in DTG can be presumed to be occurring from the sol-gel part of the composite film. That is why $1400^{\circ} \mathrm{C}$ and $300^{\circ} \mathrm{C}$ are selected after each coating processing.

X-ray diffraction patterns of the resultant CFO thick films annealed at different temperatures are exhibited in Fig. 2.

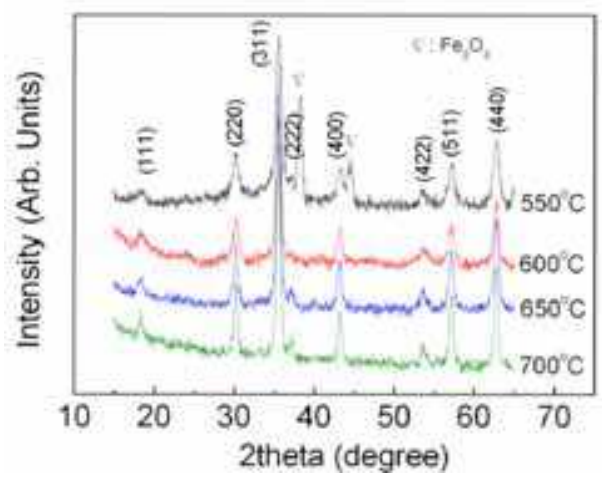

Fig. 2. XRD patterns of CFO composite thick films annealed at different temperatures.

Although major peaks due to $\mathrm{CoFe}_{2} \mathrm{O}_{4}$ are observed for the film annealed at $550{ }^{\circ} \mathrm{C}$, additional peaks (marked) assignable to $\mathrm{Fe}_{2} \mathrm{O}_{3}$ are also observed indicating the process of 
CFO formation is not complete. With the rise of the annealing temperature, complete formation of spinel phase is observed for films annealed above $600 \mathrm{\circ}$. Furthermore, these characteristic peaks of CFO phase become narrow, indicative of an increase of their grain size with increasing annealing temperature.

In order to further verify the chemical impurity in the composite thick films, micro-Raman spectroscopy is performed in Fig. 3.

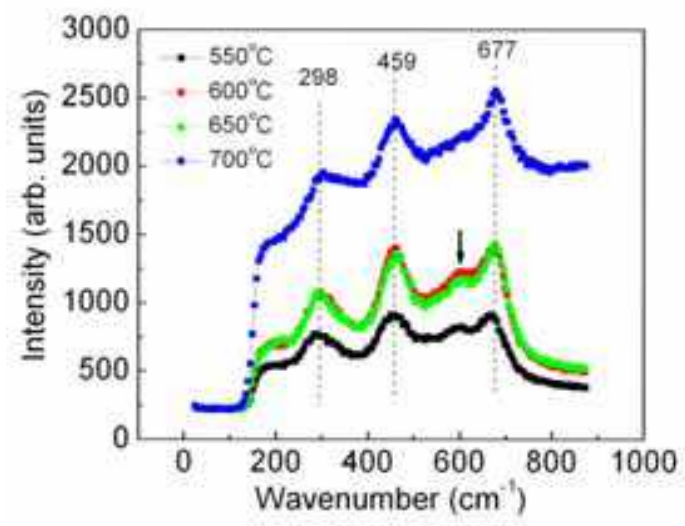

Fig. 3. Micro-Raman spectra of CFO composite thick films annealed at different temperatures.

It can be seen that three main peaks $\left(298 \mathrm{~cm}^{-1}, 459 \mathrm{~cm}^{-1}\right.$, and $\left.677 \mathrm{~cm}^{-1}\right)$ of the spinel CFO are clearly observed for all the films without any Raman shift (Ortega et al., 2008; Yu et al., 2002). Films annealed below $600{ }^{\circ} \mathrm{C}$ show the presence of a peak at $600 \mathrm{~cm}^{-1}$, which can be assigned to $\mathrm{CFO}$, supporting the inference that below $600{ }^{\circ} \mathrm{C}$, formation of $\mathrm{CFO}$ does not go to completion. In addition, these mode peaks are gradually becoming sharp with the rise of annealing temperature, suggesting a harden process of CFO modes.

Typical surface morphology and cross-sectional picture of CFO composite thick film annealed at $700{ }^{\circ} \mathrm{C}$ are shown in Fig. 4.

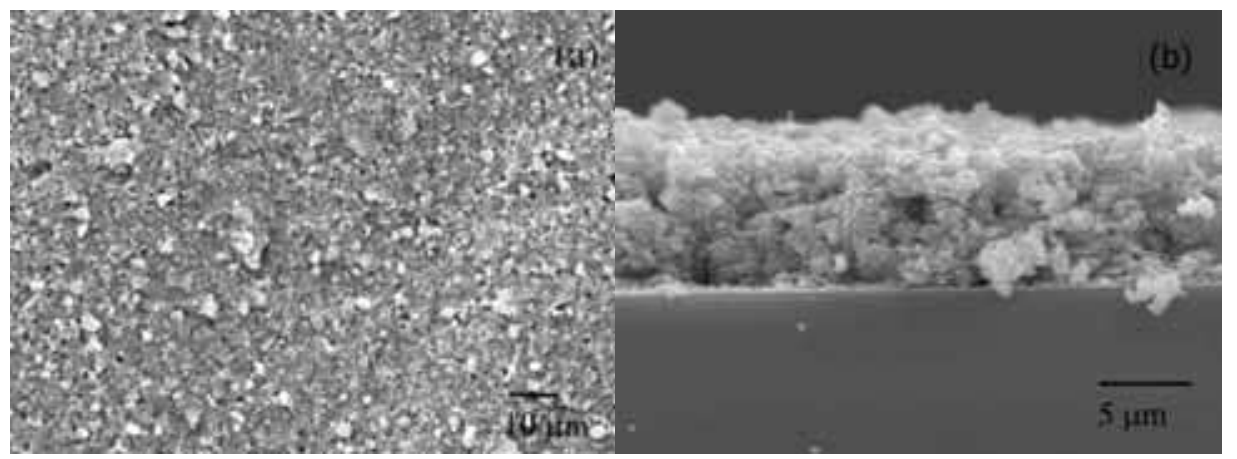

Fig. 4. Typical surface morphology (a) and cross-sectional image (b) of CFO composite thick films annealed at $700 \circ \mathrm{C}$. 
It can be seen from Fig. 4(a) that the thick films have rough, dense microstructure due to agglomeration as is the case for synthesized CFO thin films reported in the literature (Pramanik et al., 2005). The roughness can be attributed to the overlarge thickness, evidenced by its cross-sectional picture in Fig. 4(b), which also indicates a thickness closing to $10 \mu \mathrm{m}$. It is far beyond the currently reported ferrite films (Sathaye et al., 2003; Gul \& Maqsood, 2008).

In-plane magnetic hysteresis loops are shown in Fig. 5.

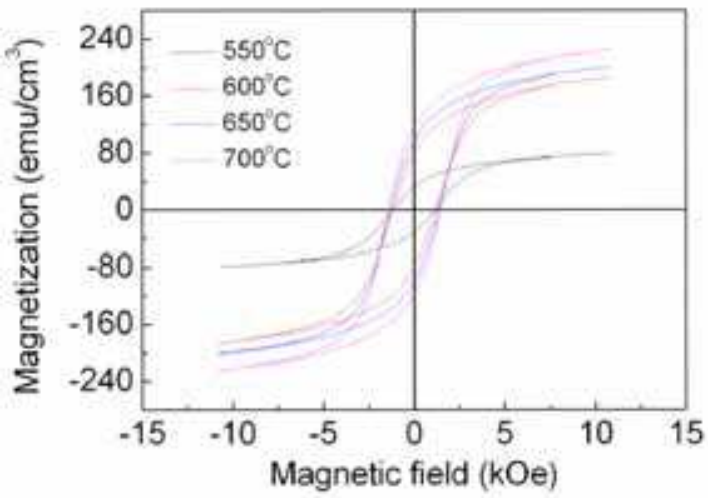

Fig. 5. Magnetic hysteresis loops of CFO composite thick films annealed at different temperatures.

It can be seen that all the films reach saturation below $8 \mathrm{kOe}$ due to the CFO ferrite thick film being in a quasi-free state with negligible shear stress from the substrate compared to chemical synthesized CFO thin film (Sathaye et al., 2003) or pulse laser deposited CFO epitaxial thin film (Lisfi \& Williams, 2003). Furthermore, the present composite thick films show an annealing temperature dependent saturation magnetization $(M s)$ and magnetic coercivity $(\mathrm{Hc})$. With increasing annealing temperature, both $\mathrm{Ms}$ and $\mathrm{Hc}$ values exhibit a monotone enhancement. The enhanced $M s$ values from 79 to $225 \mathrm{emu} / \mathrm{cm}^{3}$ are due to the enlargement of average cobalt ferrite grains, which has been demonstrated in CFO bulks and thin films (Sathaye et al., 2003; Wang et al., 2008). In the CFO thin films (Sathaye et al., 2003), the $\mathrm{Ms}$ value was reported as $300 \mathrm{emu} / \mathrm{cm}^{3}$. Compared with the present composite thick films, the higher Ms value in CFO thin film was mainly caused by higher annealing temperature.

The particles used in CFO composite thick films include two parts: one is the sol-gel synthesized particles with a small particle size of dozens of nanometer; the other is high energy ball milling modified $\mathrm{CFO}$ particles with a large average particle size of about 233 $\mathrm{nm}$. Since the latter has been presintered at $1200{ }^{\circ} \mathrm{C}$, the growth rates of both kinds of $\mathrm{CFO}$ particles under $700{ }^{\circ} \mathrm{C}$ of annealing temperature are different, resulting in non-uniform segregation causing the rough surface, which increases the coercivity of $\mathrm{CFO}$ composite thick films from 1130 to 1434 Oe. Generally speaking, high coercivity can be obtained in systems with a nanostructure or preferred orientation, such as thin films with preferred crystal texture or nanoparticles with a single domain diameter (Yin et al., 2006; Lee et al., 1998). The single domain diameter of the present CFO is about $40 \mathrm{~nm}$, which is much smaller than the average diameters of our CFO composite thick films (above $100 \mathrm{~nm}$ ), plus 
the polycrystalline state of the present thick films, evidenced by X-ray diffraction. Thus, the lower $\mathrm{Hc}$ value is mainly attributed to the magnetic multi-domain configuration of the $\mathrm{CFO}$ particles in the composites (Lee et al., 1998).

Room temperature impedance spectroscopy for the $\mathrm{CFO}$ composite thick films is exhibited in Fig. 6 for frequencies of $0.1 \mathrm{~Hz}$ to $1 \mathrm{MHz}$.

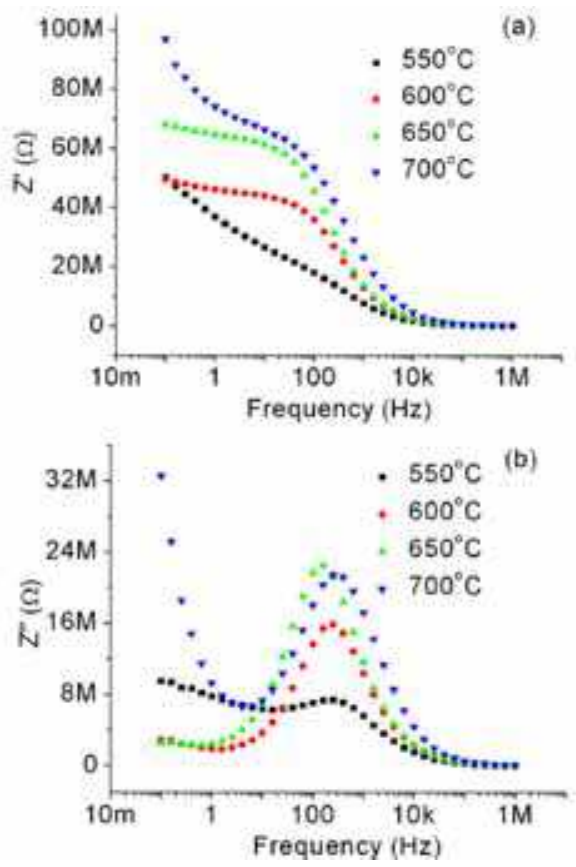

Fig. 6. Frequency dependence of real (a) and imaginary impedance (b) of CFO composite thick films at room temperature from $0.1 \mathrm{~Hz}$ to $1 \mathrm{MHz}$.

Fig. 6(a) shows the frequency dependence of impedance real part $\left(Z^{\prime}\right)$. A step-like decreasing trend is observed in real impedance spectra for all the samples from $10 \mathrm{~Hz}$ to 10 $\mathrm{kHz}$, and their specific impedance values are reduced by nearly three orders of magnitude. An apparent imaginary impedance peak appears in all the samples and becomes strong with increasing annealing temperature, as can be seen in Fig. 6(b). It can be seen that the peak frequency is around $100 \mathrm{~Hz}$, which is in the middle point of the step-like decreasing curve in real impedance spectra, indicative of a relaxation behavior. This phenomenon has not been reported in the literatures on CFO ferrite but recent studies on multiferroic $\mathrm{BiFeO}_{3}$ thin films and $\mathrm{BiFeO}_{3} / \mathrm{CoFe}_{2} \mathrm{O}_{4}$ bilayered thin films show a similar behavior (Srivastava et al., 2009; Wu \& Wang, 2009). The relaxation peak was initially observed in $\mathrm{BiFeO}_{3}$ thin films at $150{ }^{\circ} \mathrm{C}$ of measured temperature (Srivastava et al., 2009), but only $100{ }^{\circ} \mathrm{C}$ for $\mathrm{BiFeO}_{3} / \mathrm{CoFe}_{2} \mathrm{O}_{4}$ bilayered thin films (Wu \& Wang, 2009), indicating that CFO is beneficial to shift this relaxation peak to low temperature side. This is also why we observe the present relaxation behavior at room temperature. Furthermore, the present composite thick films show a similar characteristic frequency maxima $\left(f_{\max }\right)$, indicating the relaxation time is independent on annealing temperature. Additionally, above $10 \mathrm{kHz}$, both real and 
imaginary curves merge together independent of annealing temperature; while apparent annealing temperature dependent diffusion phenomena is observed below $10 \mathrm{~Hz}$. Normally, grain effects are attributed to the high frequency impedance behavior, while grain boundary effects are responsible for the low frequency phenomena (Nirose \& West, 1996). Annealing temperature independent impedance spectroscopy at high frequency side for the present composite thick films reveals that CFO grains are insensitive to the fast switch of applied alternate electric field. However, low frequency diffusion behavior indicates a remarkable grain boundaries effect, which should be attributed to the increased aggregation caused by higher annealing temperature.

In order to further investigate the effect of grains and grain boundaries of CFO composite thick films. Nyquist plots (relation between real and imaginary impedance) at room temperature for all samples are shown in Fig. 7.

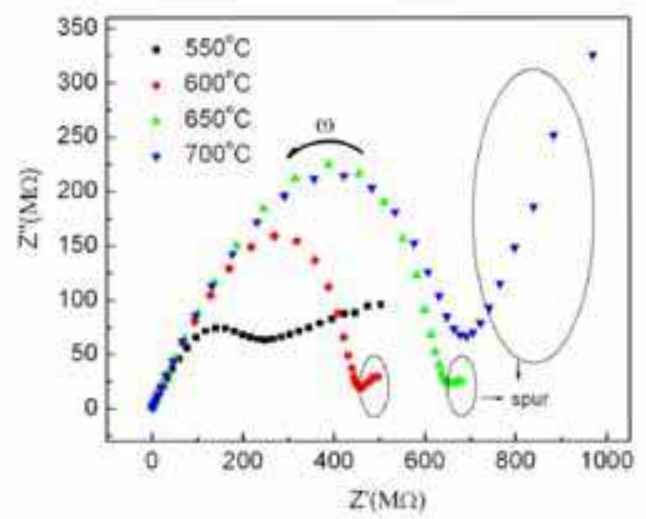

Fig. 7. Nyquist plots of CFO composite thick films annealed at different temperatures, measured in the frequency range from $0.1 \mathrm{~Hz}$ to $1 \mathrm{MHz}$.

The irregular shape of $\mathrm{CFO}$ thick film annealed at $550{ }^{\circ} \mathrm{C}$ should be attributed to the mixture of the second phase. For the sample above $600{ }^{\circ} \mathrm{C}$ of annealing temperature, it can be seen that an approximate semicircle arc is formed at the high frequency side. This semicircle arc is gradually expanded with increasing annealing temperature until $650{ }^{\circ} \mathrm{C}$, where it is almost unchanged any more compared with the one annealed at $700{ }^{\circ} \mathrm{C}$, and the absolute value of impedance also reaches the maximum, indicating that CFO grains effect reach a stable state. On the other hand, the "spur" which appeared at low frequency side is almost unchanged when annealing temperature is increased from 600 to $650{ }^{\circ} \mathrm{C}$, but when the sample is annealed at $700{ }^{\circ} \mathrm{C}$, this "spur" becomes very large, indicating an increased grain boundaries effect caused by more aggregation as mentioned above. From the impedance spectroscopy analysis, we can expect that $650 \circ \mathrm{C}$ is an optimized temperature for promising electric properties. However, to further learn the ion motion nature of three different regions in Fig. 6, AC conductivity spectra is presented below.

It is known that AC conductivity of a composite thick film can be estimated from its impedance and phase angle through the following relationship,

$$
\sigma^{*}=\frac{d}{A Z^{*}}=\frac{d}{A\left(Z^{\prime}+i Z^{\prime \prime}\right)}=\frac{d\left(Z^{\prime}-i Z^{\prime \prime}\right)}{A|Z|^{2}}
$$




$$
\sigma^{\prime}=\frac{d \cos \theta}{A|Z|}
$$

where $d$ and $A$ are the sample's thickness and its effective area, $\theta$ is the impedance phase angle and $|\mathrm{Z}|$ is the absolute value of impedance, $Z^{\prime}$ and $Z^{\prime \prime}$ are real and imaginary impedance, and $\sigma^{*}$ and $\sigma^{\prime}$ are complex conductivity and real conductivity with the latter usually known as the AC conductivity. In terms of equation (2), we can obtain the frequency dependence of $\mathrm{AC}$ conductivity in the whole measured frequency.

As can be seen in Fig. 8, three different regions are observed in ac conductivity spectra which is consistent with the three zones mentioned in impedance spectra.

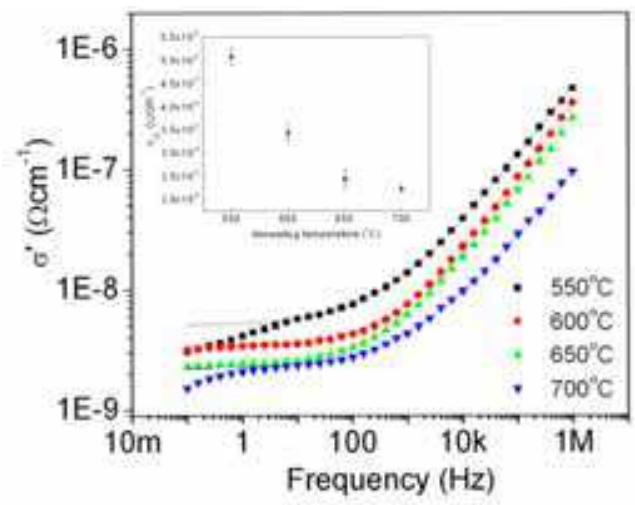

Fig. 8. AC conductivity spectra of CFO composite thick films annealed at different temperatures, the inset is the estimated DC conductivity dependence on annealing temperature.

They are corresponding to the three effects that contribute to the ac conductivity (Jame et al., 2006): (1) low frequency electrode effects; (2) intermediate frequency dc plateau; (3) high frequency ac conductivity effect. It is clearly seen that low frequency electrode effects, represented by the deviation from flat conductivity, are especially remarkable for the thick film annealed at $700{ }^{\circ} \mathrm{C}$, but very faint for the thick films annealed at 600 and $650{ }^{\circ} \mathrm{C}$. In addition, for the ac conductivity spectra at intermediate and high frequency range, the difference in the trend decreases with increasing annealing temperature due to the increased impedance values. This can be attributed to improved crystallization of composite thick films. Furthermore, the dc conductivity estimated from the power law (George et al., 2007) also indicates a decrease trend with increasing annealing temperature, as can be seen the inset picture of Fig. 8. More detailed investigations on ac conductivity spectra are conducted in the following section.

Since there is a lack of detailed impedance spectroscopy analysis of CFO thin films and bulks in the literature, data of $\mathrm{BiFeO}_{3} / \mathrm{CoFe}_{2} \mathrm{O}_{4}$ bilayered thin films is introduced for comparison to our results (Wu \& Wang, 2009), where DC plateau and NCL regime are also observed and both of them move to high frequency with increasing measured temperature. This is similar to the present case of CFO composite thick films. However, the decrease in dependence on measured temperature of $\mathrm{BiFeO}_{3} / \mathrm{CoFe}_{2} \mathrm{O}_{4}$ bilayered thin films at high frequency side is attributed to the introducing of low conductive $\mathrm{BiFeO}_{3}$, which can be also confirmed in PZT/CFO multilayered thin films (Ortega et al., 2008) where insulated PZT is 
combined together with CFO. As for the electrode polarization effect on conductivity spectra, there are no reports in the literature.

Detailed analysis for the CFO composite thick films annealed at $600{ }^{\circ} \mathrm{C}$ reveals the complicated ion motion process in this typical ferrite (Chen et al., 2010). In order to further learn the electrical behavior of this magnetic thick film, the film annealed at $600{ }^{\circ} \mathrm{C}$ is specifically studied as followed.

\section{Electrical properties}

\subsection{Impedance spectra}

Fig. 9(a) and (b) show the variation of real and imaginary parts of impedance $\left(Z^{\prime}\right.$ and $Z^{\prime \prime}$, respectively) with frequency from $100 \mathrm{~Hz}$ to $1 \mathrm{MHz}$ and temperature between 25 and $200^{\circ} \mathrm{C}$.

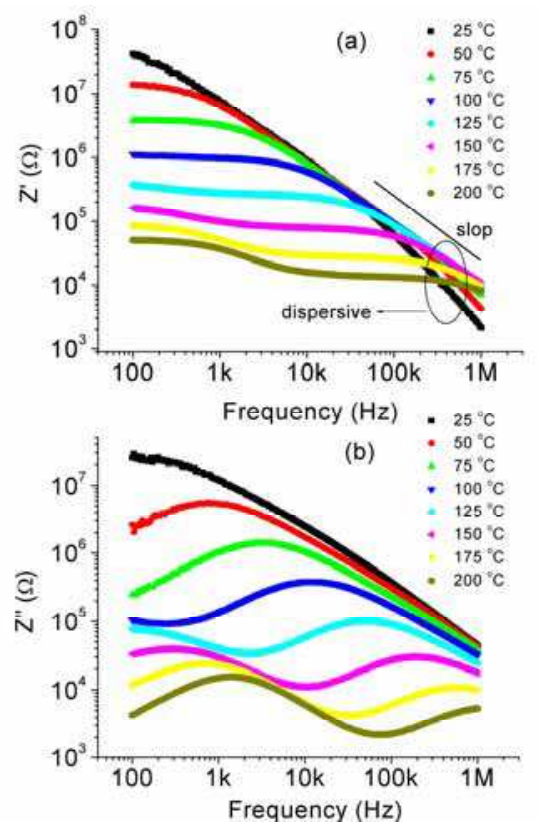

Fig. 9. Frequency dependent of real impedance (a) and imaginary impedance (b) for $\mathrm{CoFe}_{2} \mathrm{O}_{4}$ composite thick film from $100 \mathrm{~Hz}$ to $1 \mathrm{MHz}$ and between 25 and $200{ }^{\circ} \mathrm{C}$.

A temperature dependent $Z^{\prime}$ plateau is observed initially from low frequency side at $50 \circ \mathrm{C}$ followed by a nearly negative slope at high frequency side, indicating a crossover from low frequency relaxation behavior to high frequency dispersion phenomenon. Furthermore, this segment of nearly constant real impedance becomes predominated with increasing temperature, suggesting a strengthened relaxation behavior. This is similar to the behavior observed in multiferroic $\mathrm{BiFeO}_{3}$ thin films above $150{ }^{\circ} \mathrm{C}$, where a clear relaxation behavior was smoothing into the frequency window from low frequency side due to the rising temperature (Srivastava et al., 2009). When the measured temperature is above $100{ }^{\circ} \mathrm{C}$, another step-like impedance behavior is smoothing into the frequency window from the low frequency side; in the meanwhile, it pushes the previous high frequency dispersive behavior 
out of the frequency window, both remarkably relaxations are hence coexisted above $100^{\circ} \mathrm{C}$. This phenomenon has been never reported in ferrites, but an extremely weak impedance relaxation and another strong one were separately observed in different temperature ranges for recent PZT/CFO layered thin films, the strong relaxation found in high temperature was attributed to the thermal activation mechanism (Ortega et al., 2008). Fig. 9(b) shows a broad imaginary impedance peak initially at $50{ }^{\circ} \mathrm{C}$ and moves to high frequency side with increasing temperature and finally disappears at $200^{\circ} \mathrm{C}$; meanwhile, another broad peak is also appearing above $100{ }^{\circ} \mathrm{C}$ and moves to high frequency side, which corresponds to both plateau relaxations observed in real impedance spectra. The Arrhenius law is hence applied for both relaxations,

$$
\tau=\tau_{0} \exp \left(-\frac{E_{a}}{k_{B} T}\right), \tau=1 / 2 \pi f_{p}
$$

where $\tau_{0}$ is the characteristic relaxation time, $E_{a}$ is the activation energy for the relaxation process, $k_{B}$ is the Boltzmann constant, $T$ is the absolute temperature and $f_{p}$ is the peak frequency of imaginary impedance. The estimated activation energies from their respective imaginary peaks are $0.675 \mathrm{eV}$ and $0.483 \mathrm{eV}$, and the characteristic relaxation times $\tau_{0}$ are $8.01^{*} 10^{-15} \mathrm{~s}$ and $4.16^{*} 10^{-10} \mathrm{~s}$, respectively.

Nyquist plots of impedance data at different temperatures are exhibited in Fig. 10.

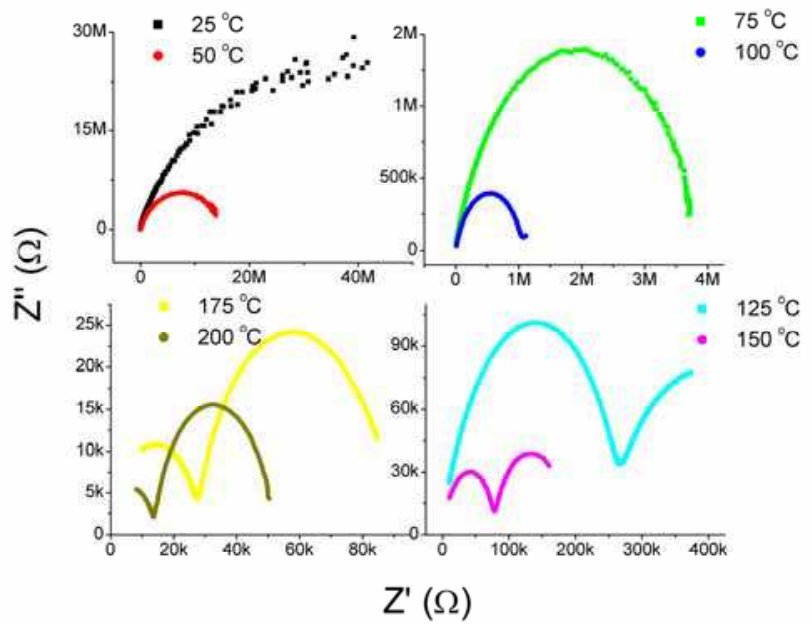

Fig. 10. Nyquist plots of $Z^{\prime}$ and $Z^{\prime \prime}$ for $\mathrm{CoFe}_{2} \mathrm{O}_{4}$ composite thick film at all measured temperatures.

At $25{ }^{\circ} \mathrm{C}$, a semicircle arc is observed and it becomes a whole semicircle till $75{ }^{\circ} \mathrm{C}$, which should be attributed to the grains effect in CFO thick film. Beginning with $100{ }^{\circ} \mathrm{C}$, a slight segment of arc is appeared from low frequency side which is connecting to this semicircle. Furthermore, with further increasing temperature, the second arc is gradually spreading till $150{ }^{\circ} \mathrm{C}$, where the original semicircle is degenerated and this arc continues to strengthen, which is corresponding to the situation of imaginary impedance spectra, where two peaks are coexisted. When the temperature finally reaches $200^{\circ} \mathrm{C}$, it can be seen that the second arc 
is nearly formed into a whole semicircle at low frequency side and the initial semicircle degenerates into a segment of arc. This suggests a process in which the grains effect is gradually replaced by grain boundaries effect with increasing temperature. Additionally, during this process, the impedance value is decreased by four orders of magnitude, which is due to thermal activation mechanism. The rise of temperature brings with an enhanced conductivity, and hence, decreasing the impedance values.

Observation of two Nyquist semicircles in Fig. 10 naturally leads us to believe that the grains effect and grain boundaries effect contribute to them like other systems (Ortega et al., 2008; Srivastava et al., 2009). However, the activation energies estimated from Arrhenius law for both semicircles suggest a different situation. Normally, the activation energy from grain boundaries was larger than that of grains (Ortega et al., 2008). That was also why the grain boundaries could play a blocking effect in many ionic oxides due to their high barrier. While the present situation is just on the contrary, the so-called grains produced activation energy is higher than that of grain boundaries, which totally cancels the barrier effect of grain boundaries. Therefore, we propose that the grain boundaries and the grains in the thick films co-contribute to the initial semicircle and the second semicircle appeared at high temperature is due to electrode polarization effect.

\subsection{Electrical modulus}

In order to demonstrate this point, electrical modulus formalism has been introduced due to its special advantage of suppressing the electrode polarization effects (Ponpandian et al., 2002). The electrical modulus is calculated from the following equation:

$$
M^{*}=M^{\prime}+j M^{\prime \prime}=j \omega C_{0} Z^{*}=j \omega C_{0}\left(Z^{\prime}-j Z^{\prime \prime}\right)
$$

where $\omega$ is the angular frequency and the geometrical capacitance is $C_{0}=\varepsilon_{0} A / d$ ( $d$ is the sample thickness, $A$ is the electrode area, and $\varepsilon_{0}$ is the permittivity of vacuum, $8.854^{*} 10^{-14}$ $\mathrm{F} / \mathrm{cm}^{-1}$ ). Through the equation (4), we can calculate the values of $M^{\prime}$ and $M^{\prime \prime}$ using the relationship $M^{\prime}=\omega C_{0} Z^{\prime \prime}$ and $M^{\prime \prime}=\omega C_{0} Z^{\prime}$. Frequency dependent $M^{\prime}$ and $M^{\prime \prime}$ at all temperatures is hence presented in Fig. 11.

As can be seen in Fig. 11(a), unlike the impedance spectroscopy, where two relaxation behaviors were well separated, the real modulus nearly showed a single relaxation behavior, which is mainly featured by a positive slope moving to high frequency side with increasing temperature. Fig. 11(b) shows that the broad peaks are being located from 25 to $100 \mathrm{oC}$, and beyond $100{ }^{\circ} \mathrm{C}$, the peak is degenerated and finally disappears above $150{ }^{\circ} \mathrm{C}$. Both of them demonstrate that the high temperature electrode polarization reflected on impedance spectroscopy is totally suppressed here (Sivakumar et al., 2007; Srivastava et al., 2009). Additionally, through careful observation we can notice an inflexion in the middle of the increasing real modulus for the samples in between 25 and $100{ }^{\circ} \mathrm{C}$; in the meanwhile, the broad peak mentioned in imaginary modulus shows a depressed behavior in the middle of its peak. This is different from the modulus peak of the kinds of ferrites, including CFO ferrite (Sivakumar et al., 2007), Ni-Zn and Mn-Zn ferrites (Sivakumar, 2007, 2008), in which only a clearly and smoothly relaxation behavior was observed. The present behavior indicated that this broad peak is constituted by two incomplete relaxation peaks, which are almost merging together. It is also why we proposed a co-contribution from grain and grain boundaries to impedance semicircle. In the modulus curves, the relaxation peak at low frequency side is contributed by grain boundaries effect and the one at high frequency side is induced by grains effect. 

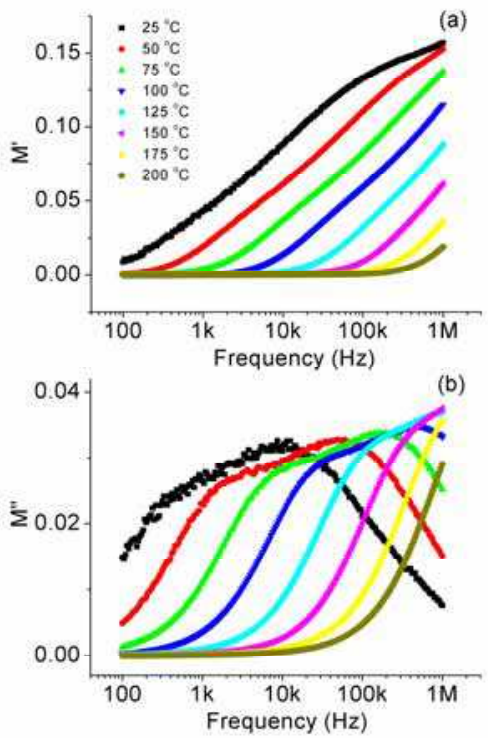

Fig. 11. Frequency dependent of real (a) and imaginary electrical modulus (b) for $\mathrm{CoFe}_{2} \mathrm{O}_{4}$ composite thick film from 25 to $200{ }^{\circ} \mathrm{C}$.

More clearly evidence can be seen in Fig. 12, complex modulus plots of CFO thick films at all temperatures are exhibited.

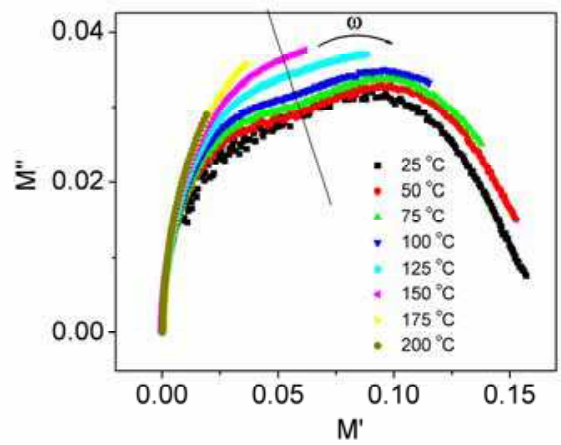

Fig. 12. $M^{\prime}-M^{\prime \prime}$ plots of $\mathrm{CoFe}_{2} \mathrm{O}_{4}$ composite thick film at all measured temperatures.

Two incomplete semicircle arcs are forming into a broad semicircle in the temperature range of $25-100{ }^{\circ} \mathrm{C}$. With further increasing temperature, only a segment of arc is left at the low frequency side, which is attributed to the grain boundaries effect induced by higher temperature. In the whole temperature range, we can see that the enhancement of measured temperature strengthens the grain boundaries effect gradually and weakens the grains effect at the same time. This is similar to many materials (Lin et al., 2008; Ahmad et al., 2009), where higher temperature stimulated the ions hopping over their barrier layers instead of hopping within their own sites. 
From the results above, we can see that two impedance relaxations are initially observed in the present $\mathrm{CFO}$ thick films, especially the coexistence phenomenon above $100{ }^{\circ} \mathrm{C}$, which was never found in literatures. The estimated activation energies from two relaxations indicate a co-effect from grains and grain boundaries to the impedance relaxation appeared at low temperature. Usually, grains effect and grains boundaries effect were being located at individual frequency and temperature range for the homogeneous materials (Srivastava et al., 2009). However, the present films show an abnormal relaxation behavior, remarkably expressed in electric modulus spectra, where the electrode polarization is suppressed. Different from a single modulus peak in other nanostructured ferrites (Sivakumar, 2007a, 2007b, 2008), a temperature dependent crossover between two peaks are observed, which may be induced by the hybridized microstructure consisting of two kinds of different sized CFO particles. The similar phenomenon reported in multiferroic PZT/CFO layered thin films demonstrated it (Ortega et al., 2008), where two electric modulus relaxations were observed, but both relaxations in this multiferroic material were located at different temperature ranges without any overlapping, which should be attributed to the large property difference between insulted PZT and low resistivity CFO phase. While the present CFO thick film is composed by the same CFO phase only with different particle sizes, it is hence expected that this special hybridized microstructure could be the main reason for the double relaxation behavior observed.

\subsection{Dielectric permittivity and loss}

Fig. 13 shows that real and imaginary dielectric constant and dielectric loss $\left(\varepsilon^{\prime}, \varepsilon^{\prime \prime}\right.$ and $\left.\tan \delta\right)$ are plotted against the frequency for all temperatures.

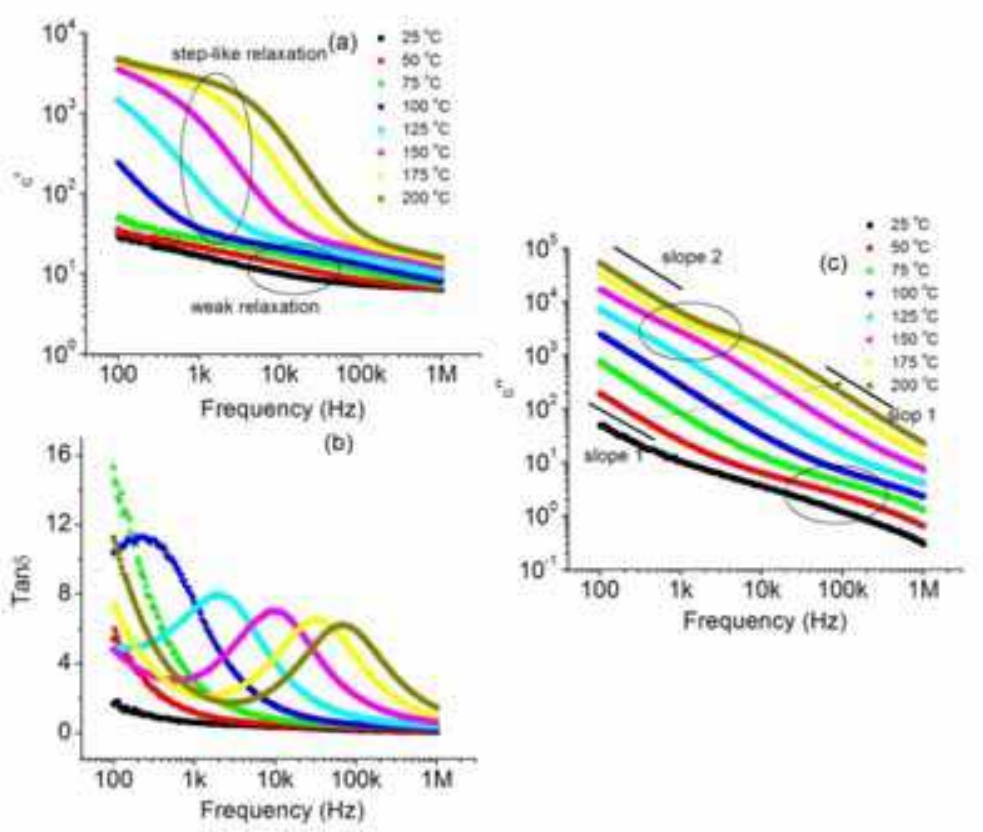

Fig. 13. Frequency dependent of real dielectric constant (a), dielectric loss (b), and imaginary dielectric constant for $\mathrm{CoFe}_{2} \mathrm{O}_{4}$ composite thick film from 25 to $200 \circ \mathrm{C}$. 
As can be seen in Fig. 13(a), it shows a strong dispersion in the real dielectric constant at low frequencies. In addition, a weak relaxation is initially observed above $1 \mathrm{kHz}$ for the sample below $100{ }^{\circ} \mathrm{C}$ and then gradually disappears at high frequency when the temperature reaches $100^{\circ} \mathrm{C}$. With further increasing temperature, a step-like relaxation behavior, which is similar to a Debye relaxation, is smoothing into the frequency window from the left side. In the meanwhile, a corresponding dielectric loss peak is observed in Fig. 13(b) from $100{ }^{\circ} \mathrm{C}$. Furthermore, this peak is moving to high frequency side along with a reduced peak loss value. It is noticed that temperature dependent peak frequency in this Figure is not obeying Arrhenius equation as other materials, suggesting this step-like relaxation a non-Debye type. Imaginary dielectric constant versus frequency is shown in Fig. 13(c), where no peak is observed in the measurable frequency range, but two weak relaxation behaviors are observed in the temperature range of $25-100{ }^{\circ} \mathrm{C}$ and $125-200{ }^{\circ} \mathrm{C}$ locating at different frequency ranges, respectively. Besides, two negative slopes of the straight lines of log-log plot are observed in Fig. 13(c). Moreover, both of them are moving to high frequency side with increasing temperature. This is a natural result of the frequency independent conduction (Dutta et al., 2004).

\subsection{AC conductivity}

Real conductivity is usually adopted for studying the ion motion of ionic oxides, glasses or melting. It can be estimated from the equation (2). The real conductivity spectra are hence presented in Fig. 14(a).

A monotonously increasing conductivity curve is observed at $25{ }^{\circ} \mathrm{C}$ and a plateau is smoothing into the frequency window from the left side above this temperature, which corresponds to the slopes in Fig. 13(c), demonstrating a constant conductivity at low frequency side. At high frequency range, there is an exponentially increasing conductivity behavior and it moves to the right side of this frequency window along with the conductivity plateau in the all temperature ranges, which was usually called as nearly constant loss regime (NCL) in the literatures (Abbas et al., 2007; Patange et al., 2009), also reflected in Fig. 13(c). According to the jumping relaxation mode (Jonscher, 1977), the frequency independent plateau at a low frequency for higher temperatures is attributed to the long-range translational motion of ions contributing to dc conductivity. According to this model, the conductivity at the low frequency region is associated with the successful hops to its neighborhood vacant site due to the available long time period; such successive jumps result in a long-range transitional motion of ions contributing to dc conductivity. At higher frequency $(>10 \mathrm{kHz})$, two competing relaxation processes may be visualized: one is the jumping ion to jump back to its initial position, i. e., unsuccessful hopping and the other is the neighborhood ions become relaxed with respect to the ion's position, i. e., successful hopping. The increase in the ratio of successful to unsuccessful ion hopping results in a more dispersive conductivity at higher frequency. For the present conductivity plateau, the data have been fitted to a double power law (Jonscher, 1977),

$$
\sigma^{\prime}=\sigma_{d c}+A f^{n_{1}}+B f^{n_{2}}
$$

where $\sigma^{\prime}$ is the real conductivity, $\sigma_{\mathrm{dc}}$ is the transitional hopping gives the long-range electrical transport in the long time limit, and coefficient $A, B$ and exponent $n_{1}, n_{2}$ are temperature and material intrinsic property dependent constants (Jonscher, 1977; Funke, 1993). The term $\mathrm{Af}^{\mathrm{n}_{1}}$ and $\mathrm{Bf}^{\mathrm{n}_{2}}$ characterize the contributions from grains and grain boundaries. As can be seen in Fig. 14(a), solid lines are perfectly fitting to the experimental data. Moreover, the estimated $\sigma_{\mathrm{dc}}$ is also obeying the Arrhenius-like law, 

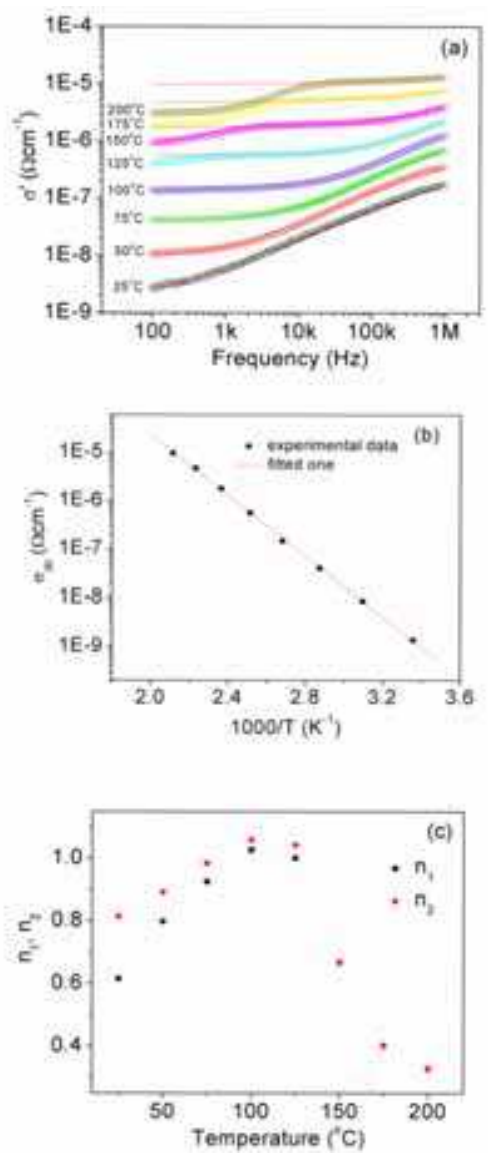

Fig. 14. Frequency dependent of real conductivity and its fitting curves from double power law (a); temperature dependent of dc conductivity and its fitting curve from Arrhenius law (b); double power parameters at all measured temperatures (c).

$$
\sigma_{d c}=\sigma_{0} \exp \left(-\frac{E_{a}}{k_{B} T}\right)
$$

where $\sigma_{0}$ is a constant, $E_{a}$ is the activation energy, $k_{B}$ is the Boltzmann constant, and $T$ is the absolute temperature, as can be seen in Fig. 14(b). This indicates that ions are more incline to their nearest neighbor hopping. Furthermore, the activation energy calculated here is closing to $0.675 \mathrm{eV}$ as mentioned above from imaginary impedance. In addition, parameter $n_{1}$ and $n_{2}$ mostly locate in the range of $(0,1)$, which corresponds to a short-range transitional hopping motion. Temperature dependent of $n_{1}$ and $n_{2}$ values are presented in Fig. 14(c), it is clear that both values are very closing to each other, which are due to the comparative grains and grain boundaries effects. Furthermore, both of them show a peak in the temperature range from 75 to $125{ }^{\circ} \mathrm{C}$, which corresponds to the onset of the crossover from the grain contribution to grain boundaries contribution well supported by frequency and temperature dependent modulus plots. Worthy of noticing is that both parameters are 
closing to 1 and even above it at 100 and $125{ }^{\circ} \mathrm{C}$, which is corresponding to the few of localized or reorientational hopping motion (Funke, 1993).

Additional, when the temperature is above $100{ }^{\circ} \mathrm{C}$, a conductivity tail is appearing at low frequency side, such as the situation happened at $125{ }^{\circ} \mathrm{C}$, which is usually believed to be electrode polarization effect (Marczak \& Diesinger, 2009; Imre et al., 2009). Followed by this tail, another plateau is observed at low frequencies with further increasing temperature. This behavior is never reported before. It is also why a whole Nyquist semicircle on electrode polarization effect is rarely found in literatures. For the present case, we can see that this electrode polarization effect reflecting on real conductivity is similar to the way of conductivity spectra resulted from the co-effect of grains and grain boundaries. Its dc plateau, which is corresponding to the slope 2 in imaginary dielectric constant, is also moving to high frequency as well as the NCL regime with the rise of temperature. Due to this part is mainly contributed by electrode polarization effect, single power law is hence applied,

$$
\sigma^{\prime}=\sigma_{d c}+A f^{n}
$$

It is noticed that the fitted $n$ value from Fig. $14(\mathrm{a})$ is 1.12 , indicating a localized or reorientational hopping motion, which should be attributed to the Au/Ti electrode layer. Furthermore, its dc conductivity is also fitted to the Arrhenius law and the estimated activation energy is nearly same to the value calculated from imaginary impedance, demonstrating again the electrode polarization contribution to the low frequency semicircle in Nyquist plots.

\section{Conclusion}

Cobalt ferrite composite thick films are prepared on $\mathrm{Pt} / \mathrm{Ti} / \mathrm{SiO}_{2} / \mathrm{Si}$ substrate by a hybrid sol-gel processing. Through annealing at different temperatures, XRD and Raman spectra indicate that pure spinel phase is formed above $600{ }^{\circ} \mathrm{C}$. A $10 \mu \mathrm{m}$ of thickness is confirmed by cross-sectional SEM imaging. Furthermore, with increasing annealing temperature, saturation magnetization and magnetic coercivity are increased. Room temperature impedance spectroscopy analysis indicates a relaxation behavior from $10 \mathrm{~Hz}$ to $10 \mathrm{kHz}$, and this relaxation behavior is strengthened with increasing annealing temperature. Complex $Z^{\prime}-Z^{\prime \prime}$ plots reveal the main contribution to the relaxation behavior is from grains for all the samples. Additionally, $650{ }^{\circ} \mathrm{C}$ of annealing temperature is believed optimal one due to a large grain boundary effect being observed at $700{ }^{\circ} \mathrm{C}$ of annealing temperature.

Detailed temperature and frequency dependent impedance spectra were conducted on the $\mathrm{CFO}$ thick films annealed at $600{ }^{\circ} \mathrm{C}$ for further electrical investigations. Two relaxations were observed in impedance spectra corresponding to both semicircles in Nyquist plots. The high frequency semicircle is induced by co-effect of grains and grain boundaries, whereas the low frequency semicircle is due to the electrode polarization effect. Electrical modulus studies demonstrate that the grain effect is decisive below $100{ }^{\circ} \mathrm{C}$, while the grain boundaries are playing a more important role above this temperature. Non-Debye relaxation is subsequently observed in dielectric spectra, and imaginary dielectric constant spectra further indicates two segments of frequency independent conductivity, which is demonstrated in real conductivity spectra. In the conductivity spectra, on one hand, the dc plateau at high frequency obeys the double power law along with two similar power 
parameters, indicative of the comparative contribution from grain and grain boundaries. The peak in temperature dependent power parameters further suggests the crossover from grain effect to grain boundaries effect. Moreover, the dc conductivity well obeys the Arrhenius law and the estimated activation energy is same to the one calculated from high frequency imaginary impedance peaks. On the other hand, the other dc plateau at low frequency obeys the power law, and its power parameter is 1.12, suggesting a localized or reorientational hopping motion probably induced by $\mathrm{Au} / \mathrm{Ti}$ layer. In addition, the activation energy calculated from its fitted dc conductivity shows the same value to the one from low frequency imaginary peaks, demonstrating the electrode polarization contribution to the low frequency Nyquist semicircle.

\section{Reference}

Abbas, S. M., Chatterjee, R., Dixit, A. K., Kumar, A. V. R., \& Goel, T. C. (2007). Electromagnetic and microwave absorption properties of $\left(\mathrm{Co}^{2+}-\mathrm{Si}^{4+}\right)$ substituted barium hexaferrites and its polymer composite. Journal of Applied Physics, Vol.101, No.7, (April 2007), pp. 074105-6, ISSN 0021-8979

Ahmad, M. M., Yamane, Y., \& Yamada, K. (2009). Structure, ionic conduction, and giant dielectric properties of mechanochemically synthesized $\mathrm{BaSnF}_{4}$. Journal of Applied Physics,Vol.106, No.7, (October 2009), pp. 074106-7, ISSN 0021-8979

Bhame, S. D., \& Joy, P. A. (2008). Effect of sintering conditions and microstructure on the magnetostrictive properties of cobalt ferrite. Journal of the American Ceramic Society, Vol.91, No.6, (June 2008), pp. 1976-1980, ISSN 0002-7820

Chen, W., Wang, Z. H., Ke, C., Zhu, W., \& Tan, O. K. (2009). Preparation and characterization of $\mathrm{Pb}\left(\mathrm{Zr}_{0.53} \mathrm{Ti}_{0.47}\right) \mathrm{O}_{3} / \mathrm{CoFe}_{2} \mathrm{O}_{4}$ composite thick films by hybrid solgel processing. Materials Science and Engineering B, Vol.162, No.1 (May 2009) pp. 4752, ISSN 0921-5107

Chen, W., Zhu, W. G., Chen, X. F., \& Wang, Z. H. (2010). Enhanced Ferroelectric and Dielectric Properties of $\mathrm{CoFe}_{2} \mathrm{O}_{4}-\mathrm{Pb}\left(\mathrm{Zr}_{0.53} \mathrm{Ti}_{0.47}\right) \mathrm{O}_{3}$ Multiferroic Composite Thick Films. Journal of the American Ceramic Society, Vol.93, No.3, (March 2010), pp. 796799, ISSN 0002-7820

Chen, W., Zhu, W., Tan, O. K., \& Chen, X. F. (2010). Frequency and temperature dependent impedance spectroscopy of cobalt ferrite composite thick films. Journal of Applied Physics, Vol.108, No.3, (August 2010), pp. 034101-7, ISSN 0021-8979

Dias, A. \& Moreira, R. L. (1999). Chemical, mechanical and dielectric properties after sintering of hydrothermal nickel-zinc ferrites. Materials Letters, Vol.39, No.1, (April 1999), pp. 69-76, ISSN 0167-577X

Dutta, S., Choudhary, R. N. P., Sinha, P. K., \& Thakur, A. K. (2004). Microstructural studies of $(\mathrm{PbLa})(\mathrm{ZrTi}) \mathrm{O}_{3}$ ceramics using complex impedance spectroscopy. Journal of Applied Physics, Vol.96, No.3, (August 2004), pp. 1607-1613, ISSN 0021-8979

Fontijin, W. F. J., van der Zaag, P. J., Feiner, L. F., Metselaar, R., \& Devillers, M. A. C. (1999). A consistent interpretation of the magneto-optical spectra of spinel type ferrites. Journal of Applied Physics, Vol.85, No.8, (April 1999), pp. 5100-5105, ISSN 0021-8979

Funke, K. (1993). JUMP RELAXATION IN SOLID ELECTROLYTES. Progress in Solid State Chemistry, Vol.22, No.2, (May 1993), pp. 111-195, ISSN 0079-6786 
George, M., Nair, S. S., Malini, K. A., Joy, P. A., \& Anantharaman, M. R. (2007). Finite size effects on the electrical properties of sol-gel synthesized $\mathrm{CoFe}_{2} \mathrm{O}_{4}$ powders: deviation from Maxwell-Wagner theory and evidence of surface polarization effects. Journal of Physics D- Applied Physics, Vol.40, No.6, (March 2007), pp. 15931602, ISSN 0022-3727

Gul, I. H., Abbasi, A. Z., Amin, F., Anis-ur-Rehman, M., \& Maqsood, A. (2007). Structural, magnetic and electrical properties of $\mathrm{Co}_{1-\mathrm{x}} \mathrm{Zn}_{\mathrm{x}} \mathrm{Fe}_{2} \mathrm{O}_{4}$ synthesized by co-precipitation method. Journal of Magnetism and Magnetic Materials, Vol.311, No.2, (April 2007), pp. 494-499, ISSN 0304-8853

Gul, I. H., Ahmed, W., \& Maqsood, A. (2008). Electrical and magnetic characterization of nanocrystalline $\mathrm{Ni}-\mathrm{Zn}$ ferrite synthesis by co-precipitation route. Journal of Magnetism and Magnetic Materials, Vol.320, No.3-4, (February 2008), pp. 270-275, ISSN 0304-8853

Gul, I. H., \& Maqsood, A. (2008). Structural, magnetic and electrical properties of cobalt ferrites prepared by the sol-gel route. Journal of Alloys and Compounds, Vol.465, No.1-2, (October 2008), pp. 227-231, ISSN 0925-8388

Imre, A. W., Schonhoff, M., \& Cramer, C. (2009). Unconventional Scaling of Electrical Conductivity Spectra for PSS-PDADMAC Polyelectrolyte Complexes. Physical Review Letters, Vol.102, No.25, (June 2009), pp. 255901-4, ISSN 0031-9007

Jame, A. R., Prakash, C., \& Prasad, G. (2006). Structural properties and impedance spectroscopy of excimer laser ablated $\mathrm{Zr}$ substituted $\mathrm{BaTiO}_{3}$ thin films. Journal of Physics D-Applied Physics, Vol.39, No.8, (April 2006), pp. 1635-1641, ISSN 0022-3727

Jonscher, A. K. (1977). Universal dielectric response. Nature, Vol.267, No.5613, (June 1977), pp. 673-679, ISSN 0028-0836

Kitamoto, Y., Kantake, S., Shirasaki, F., Abe, M., \& Naoe, M. (1999). Co ferrite films with excellent perpendicular magnetic anisotropy and high coercivity deposited at low temperature. Journal of Applied Physics, Vol.85, No.8, (April 1999), pp. 4708-4710, ISSN 0021-8979

Komarneni, S., D’Arrigo, M. C., Leonelli, C., Pellacani, G. C., \& Katsuki, H. (1998). Microwave-hydrothermal synthesis of nanophase ferrites. Journal of the American Ceramic Society, Vol.81, No.11, (November 1998), pp. 3041-3043, ISSN 0002-7820

Lee, J. G., Lee, H. M., Kim, C. S., \& Oh, Y. J. (1998). Magnetic properties of $\mathrm{CoFe}_{2} \mathrm{O}_{4}$ powders and thin films grown by a sol-gel method. Journal of Magnetism and Magnetic Materials, Vol.177, No.2, (January 1998), pp. 900-902, ISSN 0304-8853

Lin, F. D., Wang, Y. J., \& Lonergan, M. (2008). Journal of Applied Physics, Vol.104, No.10, (November 2008), pp. 103517-8, ISSN 0021-8979

Lisfi, A., \& Williams, C. M. (2003). Magnetic anisotropy and domain structure in epitaxial $\mathrm{CoFe}_{2} \mathrm{O}_{4}$ thin films. Journal of Applied Physics, Vol.93, No.10, (May 2003), pp. 81438145, ISSN 0021-8979

Marczak, M., \& Diesinger, H. (2009). Traveling wave dielectrophoresis micropump based on the dispersion of a capacitive electrode layer. Journal of Applied Physics, Vol.105, No.12, (June 2009), pp. 124511-7, ISSN 0021-8979 
Nirose, N., \& West, A. R. (1996). Impedance spectroscopy of undoped $\mathrm{BaTiO}_{3}$ ceramics. Journal of the American Ceramic Society, Vol.79, No.6, (June 1996), pp. 1633-1641, ISSN 0002-7820

Ortega, N., Kumar, A., Bhatacharya, P., Majumder, S. B., \& Katiyar, R. S. (2008). Impedance spectroscopy of multiferroic $\mathrm{PbZr}_{\mathrm{x}} \mathrm{Ti}_{1-\mathrm{x}} \mathrm{O}_{3} / \mathrm{CoFe}_{2} \mathrm{O}_{4}$ layered thin films. Physical Review B, Vol.77, No.1, (January 2008), pp. 014111-10, ISSN 1098-0121

Paike, V. V., Niphadkar, P. S., Bokade, V. V., \& Joshiw, P. N. (2007). Synthesis of spinel $\mathrm{CoFe}_{2} \mathrm{O}_{4}$ via the co-precipitation method using tetraalkyl ammonium hydroxides as precipitating agents. Journal of the American Ceramic Society, Vol.90, No.9, (September 2007), pp. 3009-3012, ISSN 0002-7820

Patange, S. M., Shirsath, S. E., Toksha, B. G., Jadhav, S. S., \& Jadhav, K. M. (2009). Electrical and magnetic properties of $\mathrm{Cr}^{3+}$ substituted nanocrystalline nickel ferrite. Journal of Applied Physics, Vol.106, No.2, (July 2009), pp. 023914-7, ISSN 0021-8979

Perron, H., Mellier, T., Domain, C., Roque, J., Simoni, E., Drot, R., \& Catalette, H. (2007). Structural investigation and electronic properties of the nickel ferrite $\mathrm{NiFe}_{2} \mathrm{O}_{4}$ : a periodic density functional theory approach. Journal of Physics-Condensed Matter, Vol.19, No.34, (August 2007), pp. 346219-10, ISSN 0953-8984

Ponpandian, N., Balaya, P., \& Narayanasamy, A. (2002). Electrical conductivity and dielectric behaviour of nanocrystalline $\mathrm{NiFe}_{2} \mathrm{O}_{4}$ spinel. Journal of Physics-Condensed Matter, Vol.14, No.12, (April 2002), pp. 3221-3237, ISSN 0953-8984

Ponpandian, N. \& Narayanasamy, A. (2002). Influence of grain size and structural changes on the electrical properties of nanocrystalline zinc ferrite. Journal of Applied Physics, Vol.92, No.5, (September 2002), pp. 2770-2778, ISSN 0021-8979

Pramanik, N. C., Fujii, T., Nakanishi, M., \& Takada, J. (2005). Preparation and magnetic properties of the $\mathrm{CoFe}_{2} \mathrm{O}_{4}$ thin films on $\mathrm{Si}$ substrate by sol-gel technique. Journal of Materials Science, Vol.40, No.16, (August 2005), pp. 4169-4172, ISSN 0022-2461

Sathaye, S. D., Patil, K. R., Kulkarni, S. D., Bakre, P. P., Pradhan, S. D., Sarwade, B. D., \& Shintre, S. N. (2003). Modification of spin coating method and its application to grow thin films of cobalt ferrite. Journal of Materials Science, Vol.38, No.1, (January 2003), pp. 29-33, ISSN 0022-2461

Sepelak, V., Baabe, D., Litterst, F. J., \& Becker, K. D. (2000). Structural disorder in the highenergy milled magnesium ferrite. Journal of Applied Physics, Vol.88, No.10, (November 2000), pp. 5884-5893, ISSN 0021-8979

Sivakumar, N., Narayanasamy, A., Ponpadian, N., \& Govindaraj, G. (2007). Grain size effect on the dielectric behavior of nanostructured $\mathrm{Ni}_{0.5} \mathrm{Zn}_{0.5} \mathrm{Fe}_{2} \mathrm{O}_{4}$. Journal of Applied Physics, Vol.101, No.8, (April 2007), pp. 084116-6, ISSN 0021-8979

Sivakumar, N., Narayanasamy, A., Chinnasamy, C. N., \& Jeyadevan, B. (2007). Influence of thermal annealing on the dielectric properties and electrical relaxation behaviour in nanostructured $\mathrm{CoFe}_{2} \mathrm{O}_{4}$ ferrite. Journal of Physics-Condensed Matter, Vol.19, No.38, (September 2007), pp. 386201-11, ISSN 0953-8984

Sivakumar, N., Narayanasamy, A., Jeyadevan, B., Joseyphus, R. J., \& Venkateswaran, C. (2008). Dielectric relaxation behaviour of nanostructured Mn-Zn ferrite. Journal of Physcis D-Applied Physics, Vol.41, No.24, (December 2008), pp. 0245001-5, ISSN 0022-3727 
Srivastava, A., Garg, A., \& Morrison, F. D. (2009). Impedance spectroscopy studies on polycrystalline $\mathrm{BiFeO}_{3}$ thin films on Pt/Si substrates. Journal of Applied Physics, Vol.105, No.5, (March 2009), pp. 054103-6, ISSN 0021-8979

Toksha, B. G., Shirsath, S. E., Patange, S. M., \& Jadhav, K. M. (2008). Structural investigations and magnetic properties of cobalt ferrite nanoparticles prepared by sol-gel auto combustion method. Solid State Communication, Vol.147, No.11-12, (September 2008), pp. 479-483, ISSN 0038-1098

Wang, Z. L., Liu, X. J., Lv, M. F., Chai, P., Liu, Y., \& Meng, J. (2008). Preparation of ferrite $\mathrm{MFe}_{2} \mathrm{O}_{4}(\mathrm{M}=\mathrm{Co}, \mathrm{Ni})$ ribbons with nanoporous structure and their magnetic properties. Journal of Physical Chemistry B, Vol.112, No.36, (September 2008), pp. 11292-11297, ISSN 1520-6106

Wu, J. G., \& Wang, J. (2009). Multiferroic behavior and impedance spectroscopy of bilayered $\mathrm{BiFeO}_{3} / \mathrm{CoFe}_{2} \mathrm{O}_{4}$ thin films. Journal of Applied Physics, Vol.105, No.12, (June 2009), pp. 124107-6, ISSN 0021-8979

Yin, J. H., Ding, J., Liu, B. H., Miao, X. S., \& Chen, J. S. (2006). Nanocrystalline Co-ferrite films with high perpendicular coercivity. Applied Physics Letters, Vol.88, No.16, (April 2006), pp. 162502-3, ISSN 0003-6951

Yu, T., Shen, Z. X., Shi, Y., \& Ding, Y. (2002). Cation migration and magnetic ordering in spinel $\mathrm{CoFe}_{2} \mathrm{O}_{4}$ powder: micro-Raman scattering study. Journal of Physics-Condensed Matter, Vol.14, No.37, (September 2002), pp. L613-L618, ISSN 0953-8984

Zhong, C. G., Jiang, Q., Fang, J. H., \& Jiang, X. F. (2009). Thickness and magnetic field dependence of ferroelectric properties in multiferroic $\mathrm{BaTiO}_{3}-\mathrm{CoFe}_{2} \mathrm{O}_{4}$ nanocomposite films. Journal of Applied Physics, Vol.105, No.4, (February 2009), pp. 044901-6, ISSN 0021-8979 


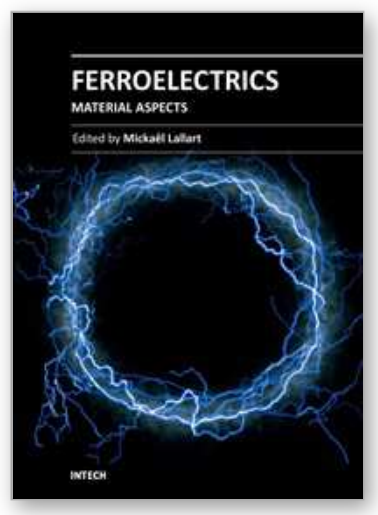

\author{
Ferroelectrics - Material Aspects \\ Edited by Dr. MickaÃ«I Lallart
}

ISBN 978-953-307-332-3

Hard cover, 518 pages

Publisher InTech

Published online 24, August, 2011

Published in print edition August, 2011

Ferroelectric materials have been and still are widely used in many applications, that have moved from sonar towards breakthrough technologies such as memories or optical devices. This book is a part of a four volume collection (covering material aspects, physical effects, characterization and modeling, and applications) and focuses on ways to obtain high-quality materials exhibiting large ferroelectric activity. The book covers the aspect of material synthesis and growth, doping and composites, lead-free devices, and thin film synthesis. The aim of this book is to provide an up-to-date review of recent scientific findings and recent advances in the field of ferroelectric materials, allowing a deep understanding of the material aspects of ferroelectricity.

\title{
How to reference
}

In order to correctly reference this scholarly work, feel free to copy and paste the following:

W. Chen and W. Zhu (2011). Deposition of CoFe2O4 Composite Thick Films and Their Magnetic, Electrical Properties Characterizations, Ferroelectrics - Material Aspects, Dr. MickaÃ«I Lallart (Ed.), ISBN: 978-953-307332-3, InTech, Available from: http://www.intechopen.com/books/ferroelectrics-material-aspects/deposition-ofcofe204-composite-thick-films-and-their-magnetic-electrical-properties-characterizatio

\section{INTECH}

open science | open minds

\section{InTech Europe}

University Campus STeP Ri

Slavka Krautzeka 83/A

51000 Rijeka, Croatia

Phone: +385 (51) 770447

Fax: +385 (51) 686166

www.intechopen.com

\section{InTech China}

Unit 405, Office Block, Hotel Equatorial Shanghai

No.65, Yan An Road (West), Shanghai, 200040, China

中国上海市延安西路65号上海国际贵都大饭店办公楼405单元

Phone: +86-21-62489820

Fax: +86-21-62489821 
(C) 2011 The Author(s). Licensee IntechOpen. This chapter is distributed under the terms of the Creative Commons Attribution-NonCommercialShareAlike-3.0 License, which permits use, distribution and reproduction for non-commercial purposes, provided the original is properly cited and derivative works building on this content are distributed under the same license. 